\title{
STUDY OF THE MECHANICAL BEHAVIOUR OF A CLAYEY SOIL UNDER NORMAL AND FROZEN CONDITIONS
}

\author{
Amit KUMAR ${ }^{1 *}$, Dharmender Kumar SONI ${ }^{1}$
}

\begin{abstract}
Lime and cement are quite compatible for stabilizing clayey soils; changes in a thermal regime may inversely affect the advantages of stabilized soil. The present study interprets changes in the mechanical behaviour of frozen and unfrozen Himalayan soil samples through an unconfined compressive strength test. The soil was treated with ground eggshell powder (3\%-9\%) and alkali activator (Sodium chloride) (2\%-6\%); it was reinforced with arbitrarily distributed polypropylene fibers (0.05\%-0.15\%). Standard 7, 14 and 21-day-old soil specimens were tested in unfrozen conditions, while fresh 21-day-old soil specimens were tested after 3, 5 and 10 freeze-thaw cycles. The design of the experiments was based on the Taguchi technique and arranged in an orthogonal array. The results of the research clearly show that poultry waste (eggshell powder) and alkaline soil stabilizer improved the strength behaviour of the subject soil. On the other hand, the polypropylene fibers played an important role in changing the brittle behaviour of the stabilized soil to ductile behaviour. The sudden collapse of a structure may be avoided by using polypropylene fibers.
\end{abstract}

\section{Address}

1 Dept. of Civil Engineering, National Institute of Technology, Kurukshetra, India

* Corresponding author: kauleamit0089@gmail.com

\section{Key words}

- Eggshell powder,

- Sodium chloride,

- Polypropylene fiber,

- Freeze-thaw,

- Mechanical properties,

- Taguchi technique.

\section{INTRODUCTION}

When road pavement construction commences, the prime consideration starts with the capability of the soil to sustain itself under normal and conditional loadings, and to be durable under different climatic conditions. The strength considerations become more important when a pavement has clayey or plastic soil beneath it, as moisture fluctuations affect the soil adversely and ultimately play a role in the failure of the pavement's service life. To eliminate or overcome the defects of the site's soil, stabilization is a possible solution. In the case of clayey soil, lime and cement are key stabilizers and have been used since the early days of soil stabilization. Many researchers have successfully confirmed and verified the use of lime and cement in clayey soil that ranges from low to high plasticity. (Kumar et al., 2014) reported that the addition of lime and phosphogypsum to the soil increased the density and consequently, its strength properties, which helped to decrease the swell index appreciably. The results might therefore be used for soil reclamation. Cement with a varying content of cement from $5 \%$ to $10 \%$ and with a varying water content from $40 \%$ to $60 \%$ showed greater strength for pavement work. After 28 days, the unconfined compression strength (UCS) was increased up to 5 times at a $10 \%$ cement content. A lower water content produces higher strength, and the soil sample undergoes a ductile to brittle transition. The cement also improved the compression index of the soil (Eskisar, 2015). Al-Swaidani et al. (2016) added natural pozzolana with lime into clayey soil. The consistency, strength and volume-related parameters were found to improve. All the changes in terms of the chemical behaviour were verified through modern techniques like X-Ray Diffraction (XRD) and Scanning Electron Microscopy (SEM). The images obtained from the XRD and SEM studies proved the presence of a cementitious gel that was formed through the chemical reactions. Khazaei and Moayedi (2017) used a petrochemical in- 
dustry-based waste along with quick lime and tested expansive soil of a low plasticity nature. The lime alone imparted brittleness to the soil, while the intrusion of the waste changed the formation of the matrix from brittle to ductile. Many other industrial wastes and by-products have also been used by different investigators to study other useful aspects of expansive and silty clay. These by-products may be broadly classified as eco-friendly for waste management. These by-products can be of an ash type like flyash or bottom ash or a solid waste type like glass fibers, tyre waste, etc. (Benessalah et al., 2016; Latifi et al., 2015; Singhi et al., 2016; Tavakoli et al., 2018; Cheng et al., 2018; Patel and Singh, 2018). Among these studies, glass fiber and tire waste performed better against freeze-thaw (FT) effects on concrete. Sometimes some bad effects of stabilizers and wastes limit their use in soil stabilization. Likewise, although cement gives satisfactory results but has high $\mathrm{CO}_{2}$ emissions during cement production, so its usage as a stabilizer is restricted, and other eco-friendly alternatives must be sought (Devi et al., 2019). The use of environmentally friendly and pure ionic stabilizers (acidic and alkaline) and other forms of lime like eggshell powder and synthetic fibers like polypropylene fiber (PPF) can be good replacements (Zhang et al., 2018; Tebaldi et al., 2016; Kaniraj and Fung, 2018; Oluwatuyi et al., 2018). Ionic stabilizers and fibers have been used by many researchers under different temperature conditions and produced excellent results. A possible reason for the improvement in the soil parameters from using ionic soil stabilizers was the cation exchange between the stabilizer and the soil minerals. Kumar and Soni (2019) found that the $\mathrm{pH}$ of clayey silt is directly proportional to the UCS value and that the high calcium content of eggshell triggers the UCS up to a certain extent. Fibers in a range of $(0.10 \%)$ improved the strength and compressibility characteristics of expansive soil (Kumar and Jain, 2015; Kumar and Jain, 2017). Natural fibers like coir fibers also proved their efficacy in the improvement of strength properties. Elastic behaviour was also found to be better than the reference mix for 28-day cured specimens (Tilak et al., 2015). Among $3 \mathrm{~mm}, 6 \mathrm{~mm}$ and $12 \mathrm{~mm}$ sized PPF in a range of $0.25 \% ; 12$-mm-sized fibers produced satisfactorily results after $10 \mathrm{FT}$ cycles (Zaimoglu et al., 2016). The behaviour of the soil was found to be improved under normal conditions, but the present study also reviewed some research under extreme temperature conditions too. The temperature conditions were comprised of repeated FT cycles on soil beneath structures. In this regard the findings of (Jigheh and Azarnia, 2017; Chaduvula et al., 2014) are noteworthy. A comparison between lime-stabilised, basalt and PPF-reinforced clay under 0-10 FT cycles indicated a decrease in UCS and was tested using the UPV technique. A linear co-relation between the UCS and UPV was also found (Boz and Sezer, 2018). The same pattern was observed by (Kravchenko et al., 2018). The effects of salt on saline soil and clay were studied by (Han et al., 2018; Liu et al., 2018), and the results were achieved using a triaxial compression test and UCS test respectively. Both researchers claimed an approximate salt concentration of $2 \%$ is enough to reduce the FT effects on soil. In another study, the tensile strength was measured using an 8-shaped mould by (Li et al., 2018), and a significant decrease in tensile strength after the ninth FT cycle was found. Although the first five FT cycles showed a noticeable reduction in strength, during the sixth to ninth FT cycles, the strength was found to be almost constant. This was due to the packing of soil particles by frequent melting and the formation of ice crystals in the soil.

Although extensive literature on cement, lime and fiber-based stabilization for clayey or other soils is available for exploration, the lacuna in the literature is the inspiration for this research. According to the best knowledge of the authors, the combined use of ESP, $\mathrm{NaCl}$ and PPF against FT cycles still needs to be explored, as there is not much information in the literature. The Taguchi technique also needs to be implemented in civil engineering.

\subsection{Motivation and scope}

Lime stabilization is the most suitable method for modifying clayey soil if the soil found at a site is not suitable for construction purposes. This kind of stabilization causes no problems if implemented in warm weather regions, but in cold regions, lime stabilization causes difficulties, particularly when the cold season lasts a long time or permafrost occurs. Keeping in mind issues like shrinkage and volumetric expansion, etc., which propagate crack formations in stabilized soil. Other natural lime sources, especially waste materials rich in calcium, may provide a possible solution to this problem. Cement stabilization is another effective solution, but high $\mathrm{CO}_{2}$ emissions during the production of cement restrain its use in soil stabilization. The present research focused on the use of waste eggshells in powdered form to evaluate possible positive outcomes in terms of an enhancement in the mechanical properties of soil. Sodium chloride $(\mathrm{NaCl})$ with negatively charged ions can be used in cation exchange for better interactions with the positive ions of calcium present in eggshell powder (ESP) and can produce gains in strength. To minimize crack propagation during freeze-thaw (FT) cycles, polypropylene fibers (PPF) were also introduced within a range as prescribed by previous studies.

The scope of the present study is to determine any changes in the mechanical behaviour of modified soil samples with respect to the parent soil samples.

\section{MATERIALS AND METHODOLOGY}

To make the research more feasible, soil was taken from cold regions of India, i.e., Jammu and Kashmir. The index properties of the soil, which were determined as (specific gravity 2.6; liquid limit $34 \%$; plastic limit 29\%; OMC $19.3 \%$ and MDD $1.72 \mathrm{~g} / \mathrm{cm}^{3}$ ) were observed in a laboratory. The examined soil was found to be the ML (silt with low plasticity) type as per a plasticity chart proposed by the Indian Standard Classification (ISC) System. An energy dispersive spectrograph (EDS) showing the minerals of the soil is given in Fig. 1. The EDS image clearly shows the available silica and traces of other minerals like alumina and magnesium, etc. Eggshell powder ( $425 \mu$ aperture sieved) was used throughout the experimentation, because milled and fine ESP react faster due to its larger surface area. An energy dispersive spectrograph of the ESP is given in Fig. 2. The high content of the calcium present in the ESP can be seen in Fig. 2.

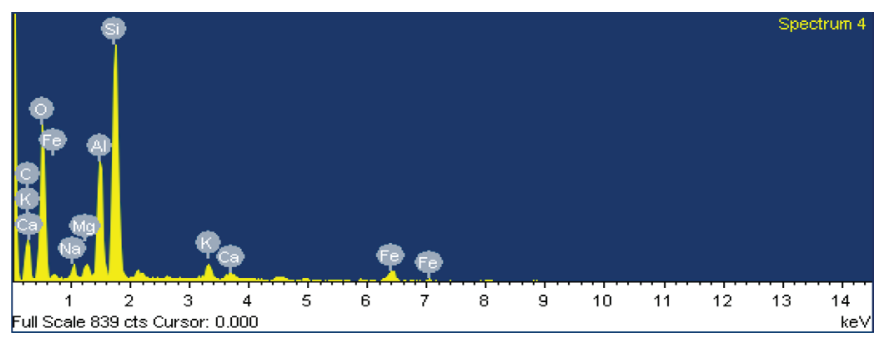

Fig. 1 Energy dispersive spectrograph of the soil

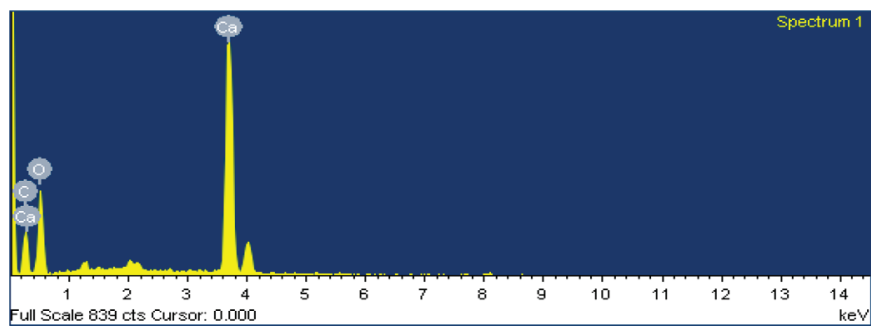

Fig. 2 Energy dispersive spectrograph of the eggshell powder 


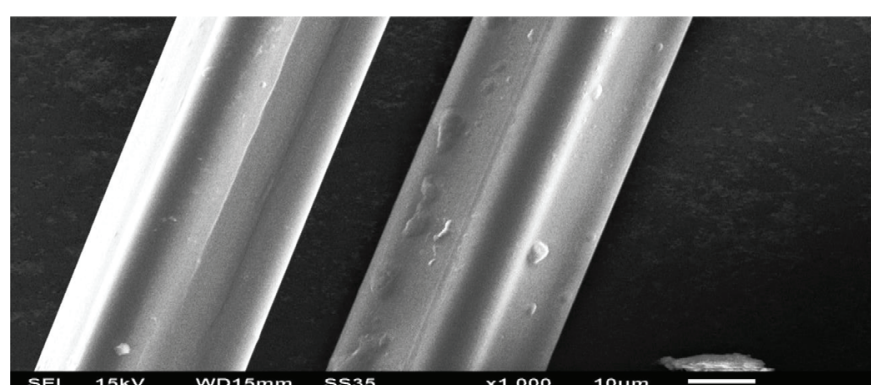

Fig. 3 Scanning electron microscopograph of the polypropylene fiber

The alkaline activator $(\mathrm{NaCl})$ was purchased from a local chemical trader. The PPF of a 12-mm size and triangular in shape was procured from Reliance India Limited. A scanning electron microscopograph (SEM) showing the PPF shape is given in Fig. 3. All the additives were mixed by weight fraction. The additives and their levels are given in Table 1. Taguchi's orthogonal array (OA) is given in Table 2.

The whole testing campaign was completed in the following phases:

1. The first phase consisted of the testing of the specimens without any temperature condition, i.e., at room temperature, when the samples were subjected to 7,14 and 21 days of curing. The samples were kept in air-tight polyethylene bags during the curing so that the moisture content was maintained till the testing.

2. The later phase consisted of the testing of the specimens cured 21 days under freeze-thaw conditions. The temperature was kept at $-20^{\circ \mathrm{C}}$ during the freezing and $20^{\circ \mathrm{C}}$ during the thawing.

3. Using the calculated signal-to-noise $(\mathrm{S} / \mathrm{N})$ ratios for the observed values under both conditions, response graphs were produced using Minitab 17 software.

The scheduling of the temperature during the freeze-thaw conditioning is shown in Fig. 4.

Tab. 1 Additives and their degree

\begin{tabular}{|c|c|c|c|}
\hline \multicolumn{4}{|c|}{ Additives } \\
\hline Degree & ESP (\%) & PPF (\%) & $\mathrm{NaCl}(\%)$ \\
\hline 1 & 3 & 0.05 & 2 \\
\hline 2 & 6 & 0.10 & 4 \\
\hline 3 & 9 & 0.15 & 6 \\
\hline
\end{tabular}

Tab. 2 Experimental mix design (Orthogonal Array)

\begin{tabular}{|c|c|c|c|}
\hline \multirow{2}{*}{ Mix Designation } & \multicolumn{3}{|c|}{ Additives } \\
\cline { 2 - 4 } & ESP (\%) & PPF (\%) & $\mathrm{NaCl}$ (\%) \\
\hline R1 & 3 & 0.05 & 2 \\
\hline R2 & 3 & 0.10 & 4 \\
\hline R3 & 3 & 0.15 & 6 \\
\hline R4 & 6 & 0.05 & 4 \\
\hline R5 & 6 & 0.10 & 6 \\
\hline R6 & 6 & 0.15 & 2 \\
\hline R7 & 9 & 0.05 & 6 \\
\hline R8 & 9 & 0.10 & 2 \\
\hline R9 & 9 & 0.15 & 4 \\
\hline
\end{tabular}

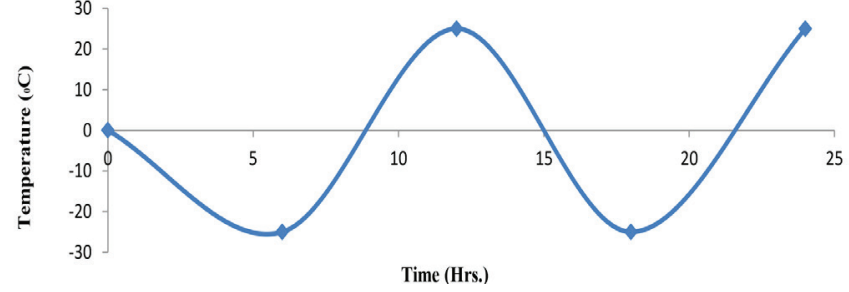

Fig. 4 Temperature schedule for the FT cycles

Before the experiments were conducted, the design of the experi-

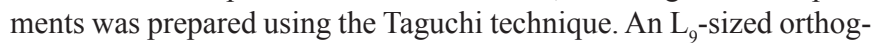
onal array was chosen for the experiments. The Taguchi technique is based on the $\mathrm{S} / \mathrm{N}$ ratio, ANOVA, and response graphs. The Taguchi technique is used to make a robust design by combining multiple performances into a single value termed "the $\mathrm{S} / \mathrm{N}$ ratio" (Viswanathan et al., 2017). The $\mathrm{S} / \mathrm{N}$ ratio is basically the ratio of the favourable to unfavourable responses from the experiments. The $\mathrm{S} / \mathrm{N}$ ratio is mainly calculated for the 'larger the better', 'smaller the better' and 'nominal the better' optimized conditions. In the present study 'larger the better' is best suited, as the UCS should be the maximum and calculated according to the following formula:

$$
\frac{S}{N}=-10 \log _{10}\left[\frac{1}{n} \sum_{i=1}^{n} \frac{1}{y_{i}^{2}}\right]
$$

Where ' $n$ ' shows the repetition frequency of a factor in a column of OA, and ' $\mathrm{y}_{\mathrm{i}}$ ' and ' $\mathrm{y}_{0}$ ' are the responses from the $\mathrm{i}^{\text {th }}$ experiment and the nominal value desired, respectively. The response graphs are used to determine the optimum setting for the best results of the experimental conditions. The optimum condition corresponds to a higher $\mathrm{S} / \mathrm{N}$ ratio from the response graph. For more details on the Taguchi technique, see Phadke (1989); Logothetis (1992); Roy (2001); Zaimoglu (2015 $\left.5^{\mathrm{a}, \mathrm{b}}\right)$ and Zaimoglu et al. (2016).

The freeze-thaw and UCS testing were done according to IS:4332 Part 4 (1968) and IS:2720 Part 10 (1991) respectively, as both of these are taken as the standard protocol for F-T and UCS testing of soil specimens. A FT cycle should be complete within 12 hours, because after 6 hours, the specimens have been found to be stable and produce no significant changes (Qi et al., 2004; Ghazavi and Roustaie, 2010).

\section{RESULTS AND DISCUSSION}

The present study was conducted to find out the consequences of freeze-thaw cycles on clayey soil and to mark the mechanical changes under normal conditions and thermal changes. The stress-strain relationship graphs of all the mixes; including the parent soil samples for 7, 14 and 21 days, are given in Figs. 5, 6, and 7 respectively.

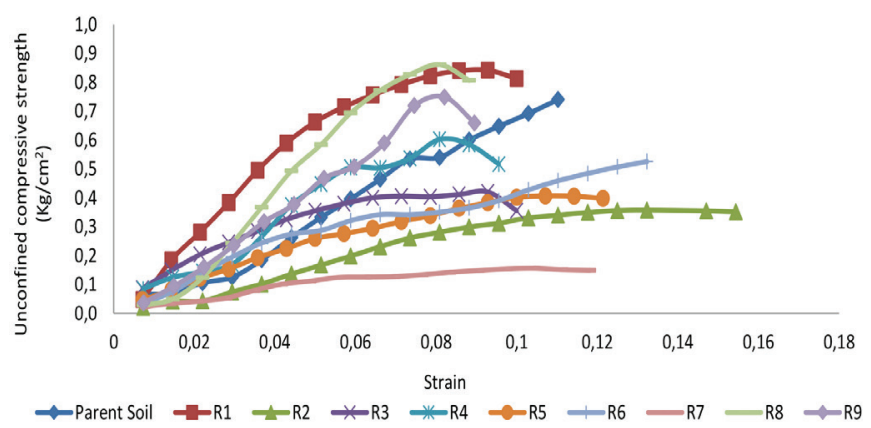

Fig. 5 Stress-strain graph (7 days) 


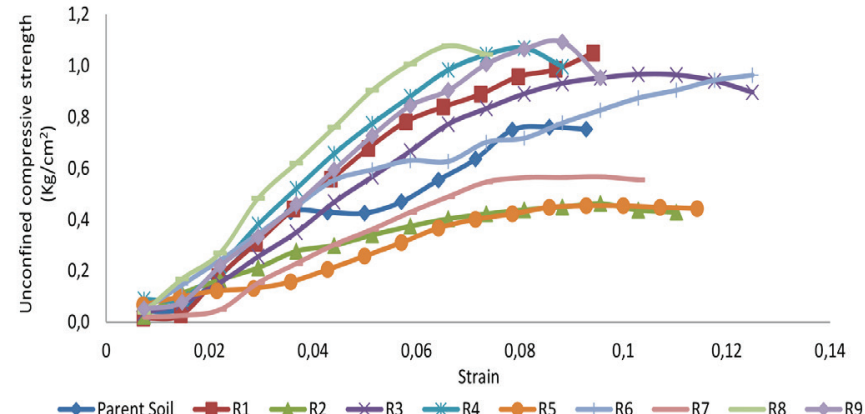

Fig. 6 Stress-strain graph (14 days)

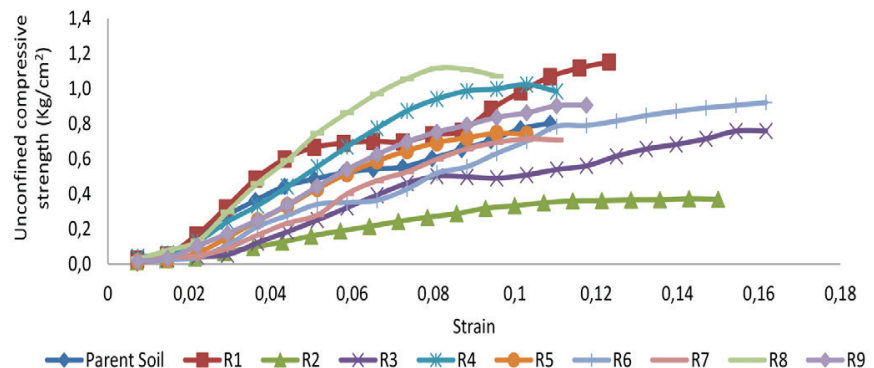

Fig. 7 Stress-strain graph (21 days)

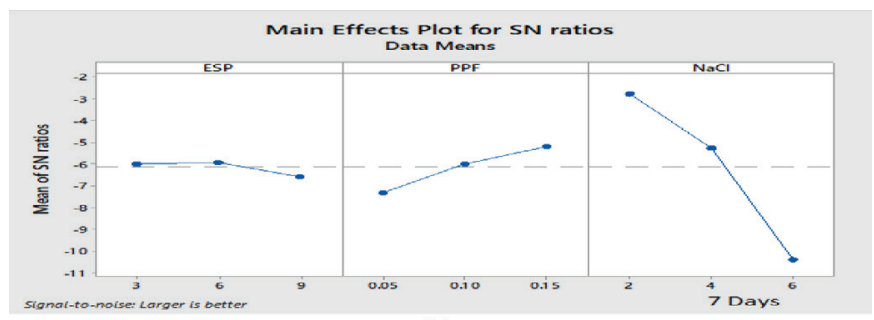

(a)

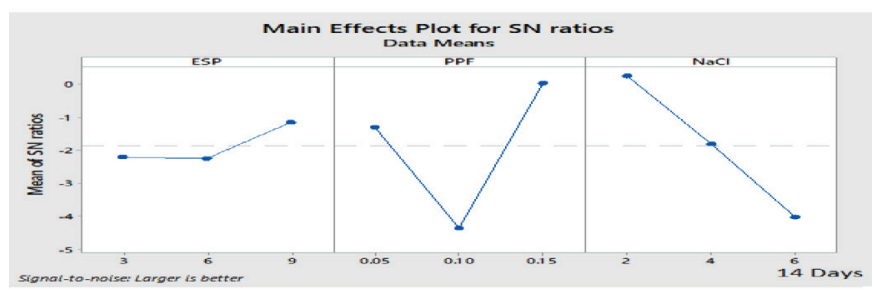

(b)

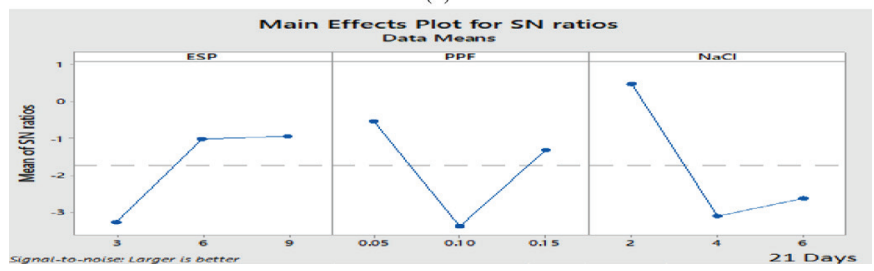

Fig. 8 Response graphs for 7, 14 and 21 days UCS

It is clear from the graphs that for the first 7 days, the additives produce insignificant results. The reason behind this phenomenon is the early age reactions between the calcium and sodium ions as discussed in previous research. These early age reactions are just enough to flocculate the soil particles together (Davidson et al., 1965; Boudaghpour and Majdzadeh, 2014). In the case of the 14 and 21-day results; the ionic reaction probably reached its peak and produced satisfactory results. The strength of the subject soil at 14 days increased from $26 \%$ to $43 \%$ with respect to the reference soil sample. The parent soil sample was chosen as the reference sample. The intrusion of fibers increased the imbibed strain in the soil-additive ma-

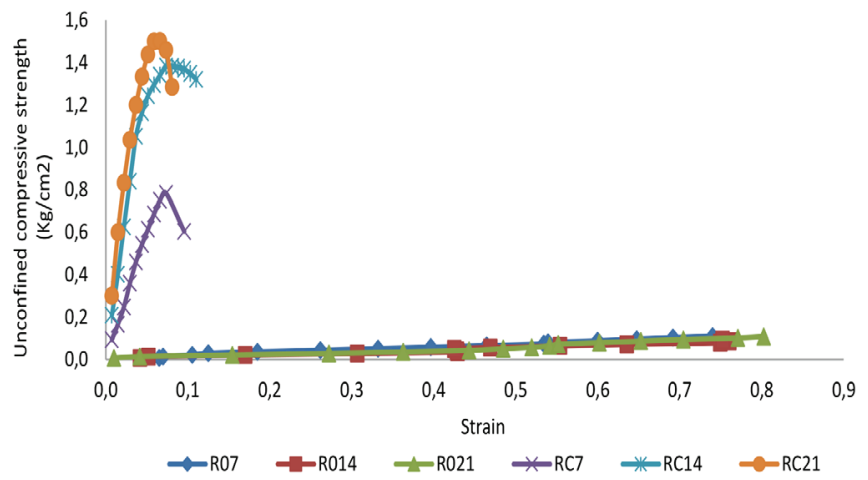

Fig. 9 Stress-strain graph for the parent soil and optimized conditions (7, 14 and 21 days), (R0 refers to the parent soil)

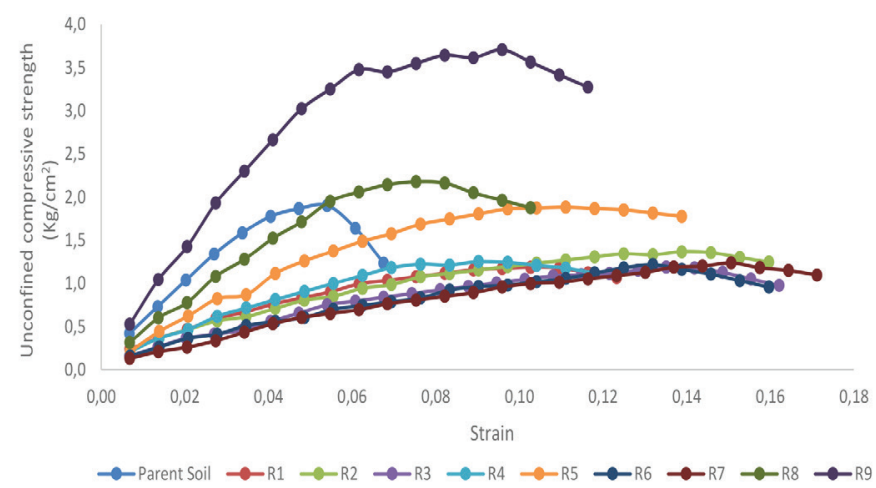

Fig. 10 Stress-strain graph (3 FT cycles)

trix, which changed the soil's behaviour from brittle to ductile, so that improvement in the strain could be reported in a range of $11 \%$ to $44 \%$. This improvement in both parameters, i.e., the strength and strain, was due to the cation exchange between the positive and negative ions of the additives and the ductile nature of the polypropylene fibers respectively. When the curing period was increased up to three weeks (21 days), the strength and endurance also increased. This increment in the strength and strain can be noted from $18 \%$ to $49 \%$ and $33 \%$ to $166 \%$ respectively. The optimum conditions to obtain the high strength and strain were taken from the response graphs and proven experimentally. The response graphs are given in Fig. 8 (a), (b) and (c). The optimized conditions correspond to the highest $\mathrm{S} / \mathrm{N}$ ratio. By observing the response graphs $\{\mathrm{ESP} 2(6 \%), \mathrm{PPF} 3(0.15 \%)$ and $\mathrm{NaCl} 1(2 \%)\}$, $\{\mathrm{ESP} 3(9 \%), \mathrm{PPF} 3(0.15 \%)$ and $\mathrm{NaCl} 1(2 \%)\}$ and \{ESP3 (9\%), PPF1 $(0.05 \%)$ and $\mathrm{NaCl} 1(2 \%)\}$ were found to be the optimized conditions; for the 7,14 and 21 days UCS respectively. The graph containing the stress-strain relationships of the optimized soil samples at 7,14 and 21 days is given in Fig. 9.

In the case of the optimized conditions, the strength was improved at all the ages, but the strain was found to be almost constant and less than the reference soil samples. The possible reason for this was the high polypropylene fiber content. Because the high content of fibers may cause a stream line crack, the strain can be affected adversely, and the sample can suddenly collapse.

The soil samples subjected to the FT cycle were tested on the UCS apparatus immediately after being taken out from the humidity chamber. The samples were therefore in a moist condition during the testing. The stress-strain graphs for the 3, 5 and 10 cycles of the FT-subjected soil samples are given in Figs. 10, 11 and 12 respectively.

The graphs show that there was a significant reduction in UCS up to 5 FT cycles for all the experimental conditions. Whereas, after 10 FT cycles, an increase was observed in the compression strength. The 


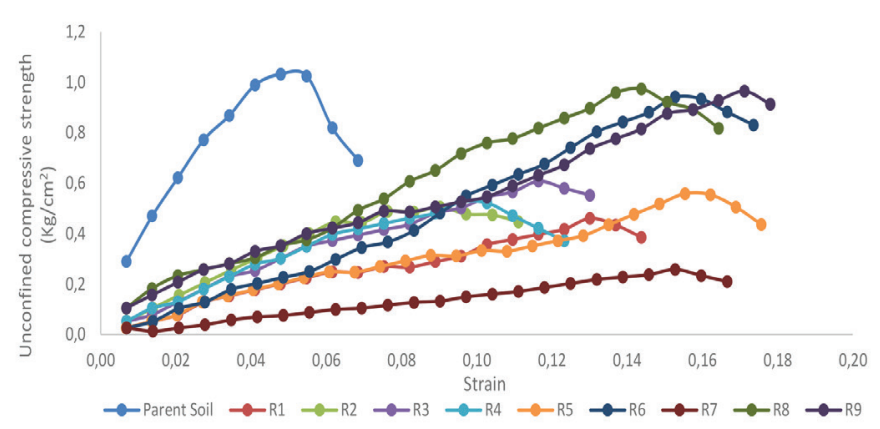

Fig. 11 Stress-strain graph (5 FT cycles)

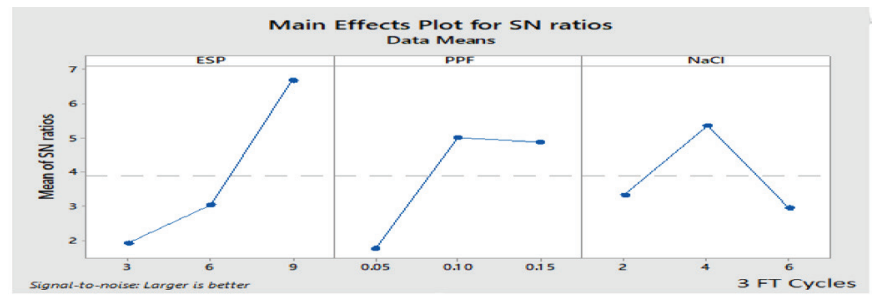

(a)

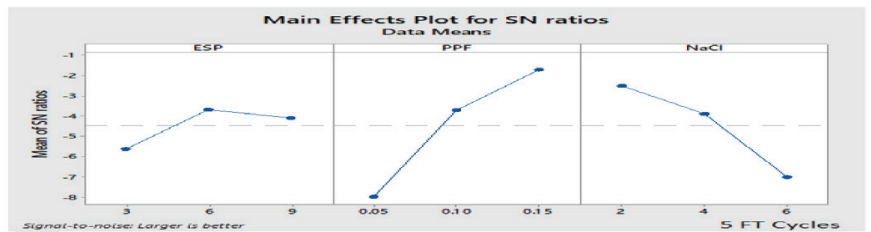

(b)

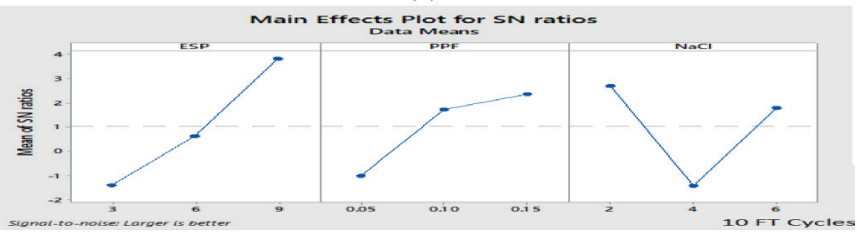

Fig. 13 Response graphs for 3, 5 and 10 FT cycles UCS

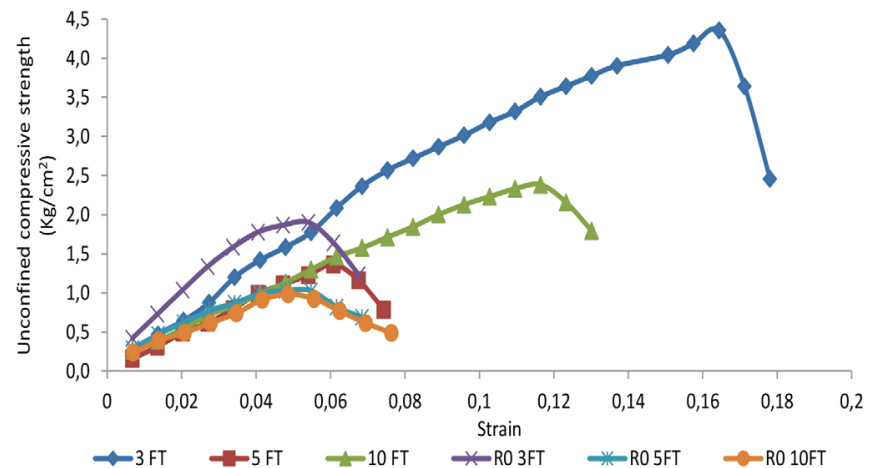

Fig. 14 Stress-strain graph for the parent soil and optimized conditions (3, 5, 10 FT Cycles), (R0 refers to the parent soil)

variations in the strength were due to the physico-chemical changes during the changes in the thermal conditions. The initial three FT cycles were responsible for the outset of the exothermic reactions; however, during the $5^{\text {th }}$ FT cycle, the existing cations were consumed by the free chloride ions for the ionic reaction; therefore, the strength was adversely affected. The next FT cycles again promoted an exothermic reaction and produced cementitious products responsible for the strength gains. The compression strength of the subjected soil samples for the 3 FT cycles varied from $15 \%$ to $95 \%$. The reduction in soil strength after 5 FT cycles was found to be from $6 \%$ to $75 \%$, whereas 10 FT cycles produced variations of $6 \%$ to $100 \%$ with respect to the reference soil samples. For the optimization, the response graphs obtained from the responses for all the cycles are given in Figs. 13 (a), (b) and (c).

The response graphs $\{\mathrm{ESP} 3(9 \%), \mathrm{PPF} 2(0.10 \%)$ and $\mathrm{NaCl} 2$ $(4 \%)\},\{\operatorname{ESP} 2(6 \%), \operatorname{PPF} 3(0.15 \%)$ and $\mathrm{NaCl} 1(2 \%)\}$ and $\{\mathrm{ESP} 3$ (9\%), PPF3 (0.15\%) and $\mathrm{NaCl1}(2 \%)\}$ showed optimized conditions for the 3, 5 and 10 FT cycles respectively. The optimum conditioned soil sample results for the 3,5 and 10 FT cycles are shown in Fig. 14.

Fig. 14 shows that there was a noticeable improvement in both, i.e., strength and strain, with respect to the reference soil samples. Improvements in the strength and strain were observed (129\% and $204 \%)$, (33\% and $25 \%)$, and (143\% and $137 \%)$, with respect to the reference soil sample for the $3^{\text {rd }}, 5^{\text {th }}$ and $10^{\text {th }}$ FT cycles respectively. The intrusion of the PPF at a high level in the optimized conditions is a possible reason for its endurance during the FT cycles, because PPF has a greater capability to resist FT effects due to its good thermal properties.

\section{CONCLUSIONS}

The unconfined compressive strength of clayey soil under normal and thermal conditions has been calculated in the present study. Changes in the mechanical behaviour in terms of the stress and strain have been studied. The following conclusions can be drawn from the above study:

1. No significant changes were found in the 7-day old soil samples in normal conditions.

2. Appreciable improvements in strength were found in the 14 and 21-day-old soil samples.

3. In normal conditions, the UCS value of the 14 and 21-dayold optimised soil samples increased to close to $82 \%$ and $95 \%$ respectively.

4. The freeze-thaw cycles promoted physico-chemical reactions in the soil samples; therefore, the cation exchange between the soil minerals and additives commenced.

5. An amalgam of the soil particles enhanced the resistance against rupture, and the sunken fibers impeded the crack propagation within the soil samples, which may be attributed to the fact that flexible polymeric fibers tend to get stretched. The resulting tensile stresses in the fibers increased the strength of the soil.

Although mechanical changes occurred in the clayey soil by using the eggshell powder, polypropylene fiber and sodium chloride in an amalgam form have been presented in the present study. The authors encourage other researchers to explore the microstructural changes and crack propagation for further study by using different materials and soil.

\section{Acknowledgement}

The authors wish to express their gratitude and deep appreciation to the faculty and laboratory assistants of the National Institute of Technology, Kurukshetra, India, for their assistance and guidance during the experiments. The authors also thank the Bridge Engineering and Structures Division, Central Road Research Institute (CRRI), New Delhi, for its unconditional help performing freeze and thaw tests in their laboratory. This research is financially supported by the Council of Scientific and Industrial Research (CSIR), New Delhi (Acknowledgement No. 141099/2K17/1; File No. 09/1050/0011/2018 EMR-1). 


\section{REFERENCES}

Al-Swaidani, A. - Hammoud, I. - Meziab, A. (2016) Effect of adding natural pozzolana on geotechnical properties of lime-stabilized clayey soil. Journal of Rock Mechanics and Geotechnica Engineering, Vol. 8, pp. 714-725. https://dx.doi.org/10.1016/j. jrmge.2016.04.002

Benessalah, I. - Arab, A. - Villard, P. - Sadek, M. - Kadri, A. (2016) Laboratory study on shear strength behaviour of reinforced sandy soil: Effect of Glass-Fiber content and other parameters. Arab J Sci Eng, Vol. 41, pp. 1343-1353. https://dx.doi.org/10.1007/ s13369-015-1912-6

Boudaghpour, S. - Majdzadeh, F. (2014) Environmental effects of lime on mechanical characteristics of stabilized closed-texture soils. Int J Geol, Vol. 8, pp. 60-64.

Boz, A. - Sezer, A. (2018) Influence of fiber type and content on freeze-thaw resistance of fiber reinforced lime stabilized clay Cold Regions Science and Technology. https://doi.org/10.1016/j. coldregions.2018.03.026

Chaduvula, U. - Desai, A. K. - Solanki, C. H. (2014) Application of triangular polypropylene fibers on soil subjected to freeze-thaw cycles. Indian Geotech J., Vol. 44, No. 3, pp. 351-356. https://doi. org/10.1007/s40098-013-0088-9

Cheng, Y. - Wang, S. - Li, J. - Huang, X. - Li, C. - Wu, J. (2018) Engineering and mineralogical properties of stabilized expansive soil compositing lime and natural pozzolans. Construction and Building Materials, Vol. 187, pp. 1031-1038. https://doi. org/10.1016/j.conbuildmat.2018.08.061

Davidson, L. K. - Dames, M. - Demirel, T. - Handy, R. L. (1965) Soil pulverization and lime migration soil-lime stabilization. HRB Record 92, National Research Council, Washington DC, pp. 103-126.

Devi, K. - Saini, B. - Aggarwal, P. (2019) Combined use of accelerators and stone slurry powder in cement mortar. Springer Nature Switzerland AG 2019, ICSWMD 2018, LNCE 21, pp. 1-8. https://doi.org/10.1007/978-3-030-02707-0_25

Eskisar, T. (2015) Influence of cement treatment on unconfined compressive strength and compressibility of lean clay with medium plasticity. Arab J Sci Eng, Vol. 40, pp. 763-772. https://doi. org/10.1007/s13369-015-1579-Z

Ghazavi, M. - Roustaie, M. (2010) The influence of freeze-thaw cycles on the unconfined compressive strength of fiber-reinforced clay. Cold Regions Science and Technology, Vol. 61, pp. 125131. https://doi.org/10.1016/j.coldregions.2009.12.005

Han, Y. - Wang, Q. - Wang, N. - Wang, J. - Zhang, X. - Cheng, S. - Kong - Y. (2018) Effect of freeze-thaw cycles on shear strength of saline soil. Cold Regions Science and Technology, Vol. 154, pp. 42-53. https://doi.org/10.1016/j.coldregions.2018.06.002

Jigheh, H. S. - Azarnia, A. (2017) Effect of liquid polymeric and lime additives on the behavior of fine-grained soil at unfrozen and freeze-thaw conditions. Indian Geotech J., Vol. 47, No. 4, pp. 529-536. https://doi.org/10.1007/s40098-0170274-2

Kaniraj, S. R. - Fung, Y. C. (2018) Influence of discrete fibers and mesh elements on the behaviour of lime stabilized soil. Pertanika J. Sci. \& Technol., Vol. 26, No. 4, pp. $1547-1570$.
Khazaei, J. - Moayedi, H. (2017) Soft expansive soil improvement by eco-friendly waste and quick lime. Arab J Sci Eng. https://dx. doi.org/10.1007/s13369-017-2590-3

Kravchenko, E. - Liu, J. - Niu, W. - Zhang, S. (2017) Performance of clay soil reinforced with fibers subjected to freeze-thaw cycles. Cold Regions Science and Technology. https://doi.org/10.1016/j. coldregions.2018.05.002

Kumar, A. - Jain, A. (2015) Effect of randomly oriented polypropylene fiber on unconfined compressive strength of black cotton soil. TC-IFES 2015, Central Leather Research Institute (CSIR-New Delhi), ISBN No. 978-93-85517-006, pp. 91

Kumar, A. - Jain, A. (2017) Effect of randomly oriented polypropylene fiber on compressibility characteristics of black cotton soil. International Journal of Advanced Technology in Engineering and Science (ISSN 2348-7550), Vol. 5, No. 2, pp. 501-511.

Kumar, A. - Soni, D.K. (2019) Significance of $p H$ in fine grained soil. ICSWMD 2018, Lecture Notes in Civil Engineering, 21, pp. 264-272. https://doi.org/10.1007/978-3-030-02707-0 32

Kumar, S. - Dutta, R. K. - Mohanty, B. (2014) Engineering properties of bentonite stabilized with lime and phosphogypsum. Slovak Journal of Civil Engineering, Vol. 22, No. 4, pp. 35 - 44. https://doi.org/10.2478/sjce-2014-0021

Latifi, N. - Marto, A. - Rashid, A. S. A. - Yii, J. L. J. (2015) Strength and physico-chemical characteristics of fly ash-bottom ash mixture. Arab J Sci Eng, Vol. 40, pp. 2447-2455. https://dx. doi.org/10.1007/s13369-015-1647-4

Li, Y. - Ling, X. - Su, L. - An, L. - Li, P. - Zhao, Y. (2018) Tensile strength of fiber reinforced soil under freeze-thaw condition. Cold Regions Science and Technology, Vol. 146, pp. 53-59. https://doi. org/10.1016/j.coldregions.2017.11.010

Liu, L. - Li, Z. - Liu, X. - Li, Y. (2018) Effect of salt content on freezing temperature and unconfined compression strength of lime-treated subgrade clay. Applied Clay Science, Vol. 158, pp. 65-71. https://doi.org/10.1016/j.clay.2018.03.022

Logothetis, N. (1992) Managing for total quality from Deming to Taguchi and SPC. Prentice Hall International Ltd., New York.

Oluwatuyi, O. E. - Adeola B. O. - Alhassan E. A. - Nnochiri, E. S. - Modupe, A. E. - Elemile, O. O. - Obayanju, T. - Akerele, G. (2018) Ameliorating effect of milled eggshell on cement stabilized lateritic soil for highway construction. Case Studies in Construction Materials xxx, e00191, pp. 1-9. https://doi.org/10.1016/j. cscm.2018.e00191

Patel, S. K. - Singh B. (2018) Shear strength and deformation behaviour of glass fiber-reinforced cohesive soil with varying dry unit weight. Indian Geotech J. https://doi.org/10.1007/s40098018-0323-5

Phadke, M. S. (1989) Quality engineering using robust design. Prentice-Hall, New Jersey.

Qi, J. L. - Zhang, J. M. - Zhu, Y. L. (2004) Influence of freezingthawing on soil structure and its soils mechanics significance. Chinese Journal of Rock Mechanics and Engineering (Supp. 2), pp. 2690-2694. 
Roy, R.K. (2001) Design of experiments using the Taguchi approach. Wiley Interscience, New York, USA.

Singhi, B. - Laskar, A. I. - Ahmed, M. A. (2016) Investigation on soil-geopolymer with slag, fly ash and their blending. Arab J Sci Eng, Vol. 41, pp. 393-400. https://dx.doi.org/10.1007/s13369$\underline{015-1677-y}$

Tavakoli, D. - Hashempour, M. - Heidari, A. (2018) Use of Waste Materials in Concrete: A review. Pertanika J. Sci. \& Technol., Vol. 26, No. 2, pp. 499 - 522.

Tebaldi, G. - Orazi, M. - Orazi, U.S. (2016) Effect of freeze-thaw cycles on mechanical behavior of lime-stabilized soil. J. Mater. Civ. Eng., Vol. 28, No. 6, pp. 1-6. https://doi.org/10.1061/(ASCE) MT.1943-5533.0001509

Tilak, B. V. - Dutta, R. K. - Mohanty, B. (2015) Effect of coir fibers on the compaction and unconfined compressive strength of Bentonite-lime-gypsum mixture. Slovak Journal of Civil Engineering, Vol. 23, No. 2, pp. 1-8. https://doi.org/10.1515/sjce-2015-0006

Viswanathan, R. - Ramesh, S. - Elango, N. - Kamesh, K. D. (2017) Temperature measurement and optimisation in machining magnesium alloy using RSM and ANOVA. Pertanika J. Sci. \& Technol., Vol. 25, No. 1, pp. 255 - 262.
Zaimoğlu, A. S. (2015) The effect of randomly distributed polypropylene fibers borogypsum fly ash and cement on freezing-thawing durability of a fine-grained soil. International Scholarly and Scientific Research \& Innovation, Vol. 9, No. 8, pp. 1093-1097. https://scholar.waset.org/1999.3/10003040

Zaimoğlu, A. S. (2015) Optimization of unconfined compressive strength of fine-grained soils modified with polypropylene fibers and additive materials. KSCE Journal of Civil Engineering, Vol. 19, No. 3, pp. 578-582. https://doi.org/10.1007/s12205-015$\underline{1425-6}$

Zaimoglu, A. S. - Calik, Y. - Akbulut, R. K. - Yetimoglu, T. (2015) A Study on freeze-thaw behavior of randomly distributed fiber-reinforced soil. Period. Polytech. Civil Eng., Vol. 60, No. 1, pp. 3-9. https://doi.org/10.3311/PPci.7533

Zaimoglu, A. S. - Tan, O. - Akbulut, R. K. (2016) Optimization of consistency limits and plasticity index of fine grained soils modified with polypropylene fibers and additive materials. KSCE Journal of Civil Engineering, Vol. 20, No. 2, pp. 662-669. https:// doi.org/10.1007/s12205-015-0540-8

Zhang, Z. - Zhang, J. - Zhang, H. (2018) Effects and mechanisms of ionic soil stabilizers on warm frozen soil. Arabian Journal for Science and Engineering, Vol. 43, pp. 5657-5666 https://doi. org/10.1007/s13369-018-3250-y 